\title{
Can Personality Traits be Related to Medical Adherence in Patients with Myocardial Infarction?
}

\author{
Brazaitiene MA ${ }^{1 *}$, Adomaitiene $\mathrm{V}^{1}$ and Gustiene \\ $\mathbf{O}^{2}$ \\ ${ }^{1}$ Department of Psychiatry, Lithuanian University of \\ Health Sciences, Lithuania \\ ${ }^{2}$ Department of Cardiology, Lithuanian University of \\ Health Sciences, Lithuania \\ *Correspondling author: Marija Audrone Brazaitiene, \\ Department of Psychiatry, Lithuanian University of \\ Health Sciences, 2 Eiveniu St, 50161, Lithuania
}

Received: May 08, 2021; Accepted: June 23, 2021;

Published: June 30, 2021

\begin{abstract}
Background: For myocardial infarction survivors, long-term pharmacotherapy is an important element of a complex treatment and a better prognosis may be achieved through better medication adherence.

Aim: The purpose of this study is to find out whether it is possible to predict medication adherence of the patients who survived myocardial infarction via assessing their personality.

\section{Design and Setting: Analytic cross-sectional study.}

Methods: The study was held in Hospital of Lithuanian University of Health Sciences Kaunas clinics (HLUHS KK) department of cardiology. Patients with ST-segment elevation myocardial infarction were randomly included and completed questionnaire before discharge from Cardiology unit. We recruited 198 patients with myocardial infarction who completed questionnaire (ICD-10 diagnoses I21.0, I21.1 or I21.2). Medical adherence association with personality was assessed with Morisky-Green medical adherence scale (MMAS-8) and the Big-Five inventory.
\end{abstract}

Results: Medical adherence was associated with conscientiousness, agreeableness, neuroticism and extraversion. There was no significant association with openness to experiences. Neuroticism negatively affected medical adherence. It was determined, that conscientiousness, agreeableness and extraversion positively affected medical adherence.

Conclusion: This study demonstrated that good medical adherence in patients with ST-segment elevation myocardial infarction was associated with higher scores in conscientiousness and agreeableness personality traits and lower scores in neuroticism.

Keywords: Personality; Medical adherence; Treatment; Myocardia infarction

\section{Introduction}

In 2019, incidence of acute or subsequent myocardial infarction (ICD-10-AM codes I21-I22) was 3,55 per 1000 residents of Lithuania (4,6 for men and 2,63 for women) [1] and mortality from acute myocardial infarction (ICD-10-AM code I21) was 40,76 per 100 000 residents of Lithuania (46,31 for men and 35,95 for women) [2]. For myocardial infarction survivors, long-term pharmacotherapy is an important element of a complex treatment and a better prognosis may be achieved through better medication adherence [3], however, the data suggest that adherence of a number of patients is not sufficient [4-6]. In order to utilize the most effective measures to optimize treatment and achieve best results, it is crucial for both healthcare specialists and the patients themselves to firstly discover the factors that could possibly contribute to poor adherence. Studies that investigated influences on medication adherence in patients after myocardial infarction focused on such variables as demographic, economic, psychosocial (depressive symptoms, stress), patient (gender, age) and health belief-related factors, medical comorbidities were also considered [5,7]. It is of note that these studies did not include patient's personality, which is an important patient factor
[8], thus its role as a risk factor for poor adherence after myocardial infarction is yet to be explored.

The key concept of personality, as the Five Factor Model describes it, can be assessed through evaluation of the following personality domains: agreeableness, conscientiousness, neuroticism, extraversion and openness to experience $[9,10]$. Agreeableness describes motivation to maintain positive relations with others, it is related to such facets as cooperation, understanding and pleasantness. Conscientiousness depicts orderliness, efficiency and dutifulness. Neuroticism defines the inverse of toughness, happiness and stability. Openness to experience is associated with intellect, reflection and ingenuity. Extraversion represents gregariousness and assertiveness.

Among the literature exploring the role of personality on adherence, there is a study by Iakovleva et al. [11] that confirms the need for research on various patient factors. The data were collected from 100 people who suffered from coronary heart disease and underwent coronary artery bypass grafting. Statistical analysis revealed that when the patients were divided into three groups (according to adherence), the adherent group scored significantly higher on conscientiousness and lower on neuroticism compared to non-adherent group. There
J Fam Med - Volume 8 Issue 5 - 2021

ISSN : 2380-0658 | www.austinpublishing group.com

Brazaitiene et al. (C) All rights are reserved
Citation: Brazaitiene MA, Adomaitiene $\mathrm{V}$ and Gustiene O. Can Personality Traits be Related to Medical Adherence in Patients with Myocardial Infarction?. J Fam Med. 2021; 8(5): 1258. 
was also a tendency to score higher on agreeableness and there was no statistical significance for extraversion and openness as well as for the differences between the partial-adherence group.

There are also many other studies that reveal the associations between personality traits of the Five Factor Model and adherence to treatment in patients suffering from various conditions. Ko et al. [12] demonstrate that a high level of conscientiousness were associated with better medication adherence in rheumatoid arthritis patients. Hazrati-Meimaneh et al. [13] found that neuroticism indicated a negative association with medication adherence. Positive associations were found between medication adherence and personality traits, including extraversion, agreeableness, and conscientiousness in patients with type 2 diabetes. Skinner et al. [14] proposed that even though the independent association between conscientiousness and glycated hemoglobin was not found, this personality trait was still important for patients with type 2 diabetes as it was related to lower body mass index, being less likely to smoke and more likely to perform beneficial self-care behaviours as blood glucose measurements and appropriate medication taking. The positive link between conscientiousness and medication adherence is also confirmed in the meta-analysis by Molloy et al. [15]. Toelle et al. [16] found that high neuroticism scores and a previous asthma hospital admission were associated with non-adherence to prescribed daily inhaled corticosteroid in asthma patients. All this research reveals the importance of personality on adherence to treatment and implements the idea of a possibility to interfere and improve the situation when a simple evaluation of the patient's personality results in prediction that adherence will not be sufficient. Therefore, further studies are required to better understand the role of personality on patient's beneficial health-related behaviours.

The aim of this study was to find out whether it is possible to predict medication adherence of the patients who survived myocardial infarction via assessing their personality in accordance to the Five Factor Model. The differences in adherence and personality dimensions regarding gender were also inspected.

\section{Methods}

\section{Study design and population}

The study was held in Hospital of Lithuanian University of Health Sciences Kaunas clinics (HLUHS KK) department of cardiology. Patients with ST-segment elevation myocardial infarction were randomly included and completed questionnaire between January 2017 and November 2018 before discharge from Cardiology unit. Patients with diagnosis of ST-segment elevation myocardial infarction completed questionnaire (ICD-10 diagnoses I21.0, I21.1 or I21.2). Patients with self-reported history of psychiatric illness were eliminated. Patients had to be capable to understand study design and sign informed consent.

\section{Variables}

Medical adherence association with personality was assessed with: Morisky-Green Medical Adherence Scale (MMAS-8) and the Big-Five inventory. The MMAS- 8 questionnaire consists of 8 items, which are rated by the patient. A higher score means a better medical adherence. Patients scored less than 6 points were assigned as having low medical adherence, from 6 to less than 8-medium and 8-high. The Big-Five inventory evaluated personality dimensions: extraversion, consciousness, agreeableness, neuroticism and openness to experiences.

\section{Statistical analysis}

Categorical variables describing sociodemographic characteristics are presented as percentages. Quantitative scores are presented as means and Standard Deviations (SD). Parametrical Student's t test was applied to compare quantitative variables between two groups and analysis of variances (ANOVA) was applied to compare among more than two groups. The results were considering as statistically significant if $\mathrm{p}<0.05$. Data analysis was performed using the statistical analysis program IBM SPSS, version 21 .

\section{Results}

The initial population was 200, of which 2 were eliminated. We recruited 198 patients with myocardial infarction (Table 1), whose sociodemographic characteristics were: male gender $73,7 \%$, mostly aged 65 years or more $52,5 \%$, had more than 11 year of education $64,1 \%$, lived with partner $72,8 \%$, were unemployed $56,6 \%$ and lived in the city $67,2 \%$.

The difference between mean age of male and female was not statistically significant $(\mathrm{p}=0.082)$. There were no association determined between adherence to medication, extraversion, neuroticism, openness to experiences and the sex of the subjects (Table 2). However, female scored higher on conscientiousness and agreeableness compared to male $(28,60(5,24)$ vs $25,96(4,85))$.

It turns out that almost every second subject of our study had poor medical adherence $(48 \%)$, every third $(31 \%)$ regular and every fifth (21\%) good medical adherence.

We determined, that low Morisky-Green scores was significantly Table 1: Sociodemographic characteristics of patients with myocardial infarction.

\begin{tabular}{|l|c|}
\hline \multicolumn{1}{|c|}{ Characteristic } & $\mathrm{n}(\%)$ \\
\hline Sex & $146(73,7)$ \\
\hline Male & $52(26,3)$ \\
\hline Female & \\
\hline Age (years) & $94(47,5)$ \\
\hline$<65$ & $104(52,5)$ \\
\hline$\geq 65$ & \\
\hline Education level (years) & $71(35,9)$ \\
\hline$\leq 11$ & $127(64,1)$ \\
\hline$>11$ & \\
\hline Family type & $144(72,8)$ \\
\hline Live in pair & $54(27,2)$ \\
\hline Single & $133(67,2)$ \\
\hline Livelyhood & \\
\hline Employed & \\
\hline Unemployed & \\
\hline Residence & \\
\hline City & \\
\hline Countryside & \\
\hline & \\
\hline
\end{tabular}


Table 2: Adherence to treatment and personality traits according to gender.

\begin{tabular}{|l|c|c|c|}
\hline & $\begin{array}{c}\text { Male } \\
\text { Mean (SD) }\end{array}$ & $\begin{array}{c}\text { Female } \\
\text { Mean (SD) }\end{array}$ & $\mathrm{P}$ \\
\hline Medical adherence & $5,78(1,92)$ & $5,84(1,70)$ & 0,983 \\
\hline Extraversion & $24,14(4,36)$ & $23,44(5,50)$ & 0,503 \\
\hline Conscientiousness & $25,96(4,85)$ & $28,60(5,24)$ & 0,001 \\
\hline Agreeableness & $25,68(5,11)$ & $28,17(6,03)$ & 0,001 \\
\hline Neuroticism & $15,88(4,87)$ & $17,38(6,15)$ & 0,087 \\
\hline Openness to experiences & $19,46(4,69)$ & $18,69(5,83)$ & 0,223 \\
\hline
\end{tabular}

Table 3: Association between personality and adherence to medical treatment.

\begin{tabular}{|c|c|c|c|c|c|}
\hline \multicolumn{2}{|c|}{} & $\begin{array}{c}\text { Poor } \\
\text { Mean (SD) }\end{array}$ & $\begin{array}{c}\text { Regular } \\
\text { Mean (SD) }\end{array}$ & $\begin{array}{c}\text { Good } \\
\text { Mean (SD) }\end{array}$ & P \\
\hline \multirow{4}{*}{$\begin{array}{c}\text { Personality } \\
\text { traits }\end{array}$} & Extraversion & $23,52(3,87)$ & $23,92(5,45)$ & $25,00(5,06)$ & 0,221 \\
\cline { 2 - 7 } & Conscientiousness & $24,77(4,93)$ & $28,45(4,37)$ & $28,21(4,96)$ & $<0,001$ \\
\cline { 2 - 7 } & Agreeableness & $24,43(5,41)$ & $27,77(5,27)$ & $28,48(4,41)$ & $<0,001$ \\
\cline { 2 - 7 } & Neuroticism & $17,49(4,41)$ & $14,98(5,75)$ & $15,48(5,74)$ & 0,007 \\
\cline { 2 - 7 } & $\begin{array}{c}\text { Openness to } \\
\text { experiences }\end{array}$ & $19,64(4,65)$ & $18,84(5,77)$ & $19,02(4,62)$ & 0,244 \\
\hline
\end{tabular}

related to low conscientiousness, agreeableness and high neuroticism, which indicates that individuals who rated low conscientiousnes and agreeablenes personality traits were more disposed to a non adherent behaviour and indivicuals with high neuroticism scores were prone to poor medical adherence. Meanwhile good medical adherence was related to high conscientiousness, agreeableness and low neuroticism. There was no significant associations between MMAS-8 scores and extraversion or openness to experiences (Table 3).

\section{Discussion and Conclusion}

Results show no significant correlation between medication adherence and respondents gender, but represent that women have higher consciousness and agreeableness values in comparison with men.

However, results show that post-myocardial infarction patients' personality traits would affect medication adherence. Specifically, results indicate, that poor medical adherence is related to low means of consciousness and agreeableness together with high means of neuroticism values. While on a contrary, good medical adherence is related to high means of consciousness and agreeableness together with low means of neuroticism. What is more, analyses show that patients compliance in a treatment is affected positively by conssiousness and agreeableness and negatively by neuroticism. Our data are compatible with the data published by foreign authors. Some of the studies found only a relationship between neuroticism and poor-adherence $[17,18]$. Others identified the negative effect of neuroticism and the importance of consiousness and/or aggreeableness on the success of a treatment [19-21].

However, our analysis provides some new information on which personality traits do have highest impact on medical adherence. While all three personality dimensions (consciousness, agreeableness, neuroticism) have statistically significant connection with medical adherence, consciousness and agreeableness have a greatest effect on adherence in general. This particular data was evaluated with a multiple regression analyses where only those two personality dimensions have a statistically significant values of impact.
Nevertheless, the combination of neuroticism and extraversion might lead to a greater levels of medication knowledge [22] and so possibly to a better medication adherence.

Research shows that every second patient in a study has poor adherence to medication and this level of collaboration is significantly related to neuroticism. Neuroticism is a corresponding characteristic of Type D personality [23] and this type of personality is frequently observed in coronary artery disease patients [24]. Therefore, it is important to continue further studies in this field to know the exact causes of this phenomenon to prevent post-myocardial infarction patients from possible recurrent cardiovascular events, hypertension, depression and anxiety in a future. Authors internationally noticed a strong association between Type D personality, poor adherence and these symptoms $[25,26]$.

In terms of implications for clinical practice, assessment of personality traits might help to find the myocardial infarction patients that are in need for extra attention and motivation and be the tool to improve the course of a treatment and recovery. Foreign authors did a research on patients after anterior cruciate ligament reconstruction surgery, to measure how their personality characteristics affect the rehabilitation adherence. Results indicate that those with low level of consciousness and agreeableness may need extra attention or motivation to improve the adherence [27].

This study demonstrated that good medical adherence in patients with ST-segment elevation myocardial infarction was associated with higher scores in conscientiousness and agreeableness personality traits and lower scores in neuroticism.

\section{References}

1. Health Statistics Portal of Institute of Hygiene.

2. Health Statistics Portal of Institute of Hygiene.

3. Ibanez B, James S, Agewall S, Antunes MJ, Bucciarelli-Ducci C, Bueno H, et al. 2017 ESC Guidelines for the management of acute myocardial infarction in patients presenting with ST-segment elevation: The Task Force for the management of acute myocardial infarction in patients presenting with STsegment elevation of the European Society of Cardiology (ESC). Eur Heart J. 2018; 39: 119-177.

4. Bansilal S, Castellano JM, Garrido E, Wei HG, Freeman A, Spettell C, et al. Assessing the Impact of Medication Adherence on Long-Term Cardiovascular Outcomes. J Am Coll Cardiol. 2016; 68: 789-801.

5. Crowley MJ, Zullig LL, Shah BR, Shaw RJ, Lindquist JH, Peterson ED, et al. Medication Non-Adherence After Myocardial Infarction: An Exploration of Modifying Factors. J Gen Intern Med. 2015; 30: 83-90.

6. Kotseva K, De Backer G, De Bacquer D, Rydén L, Hoes A, Grobbee D, et al Lifestyle and impact on cardiovascular risk factor control in coronary patients across 27 countries: Results from the European Society of Cardiology ESCEORP EUROASPIRE V registry. Eur J Prev Cardiol. 2019; 26: 824-835.

7. Eindhoven DC, Hilt AD, Zwaan TC, Schalij MJ, Borleffs CJW. Age and gender differences in medical adherence after myocardial infarction: Women do not receive optimal treatment-The Netherlands claims database. Eur J Prev Cardiol. 2018; 25: 181-189.

8. Yap AF, Thirumoorthy $\mathrm{T}, \mathrm{K}$ wan $\mathrm{YH}$. Systematic review of the barriers affecting medication adherence in older adults. Geriatr Gerontol Int. 2016; 16: 1093-1101.

9. Soto $\mathrm{CJ}$, John OP. The next Big Five Inventory (BFI-2): Developing and assessing a hierarchical model with 15 facets to enhance bandwidth, fidelity, and predictive power. J Personal Soc Psychol. 2017; 113: 117-143.

10. Allen TA, DeYoung CG. Oxford handbook of the five factor model. Widiger 
TA, editor. New York: Oxford University Press. 2017.

11. lakovleva M, Shchelkova O, Lubinskaya E, Nikolaeva O. Adherence to treatment after CABG in terms of patients' personality. SHS Web Conf. EDP Sciences. 2018; 40: 02011.

12. Ko KM, Moon SJ, Koh JH, Pae CU, Min JK. Contribution of personality traits, psychological factors, and health-related quality of life to medication adherence in patients with rheumatoid arthritis. Yonsei medical journal. 2020; 61: 406.

13. Hazrati-Meimaneh Z, Amini-Tehrani M, Pourabbasi A, Gharlipour Z, Rahim $F$, Ranjbar-Shams $P$, et al. The impact of personality traits on medication adherence and self-care in patients with type 2 diabetes mellitus: The moderating role of gender and age. Journal of Psychosomatic Research. 2020; 13: 110-178.

14. Skinner TC, Bruce DG, Davis TME, Davis WA. Personality traits, selfcare behaviours and glycaemic control in Type 2 diabetes: The Fremantle Diabetes Study Phase II. Diabet Med. 2014; 31: 487-492.

15. Molloy GJ, O'Carroll RE, Ferguson E. Conscientiousness and Medication Adherence: A Meta-analysis. Ann Behav Med. 2014; 47: 92-101.

16. Toelle BG, Marks GB, Dunn SM. Psychological and Medical Characteristics Associated with Non-Adherence to Prescribed Daily Inhaled Corticosteroid. Journal of personalized medicine. 2020; 10: 126.

17. Nakano T, Kodaka F, Tsuneoka H. Differences in Neuroticism Between Patients with Glaucoma Who Have Discontinued Visits to Ophthalmologists and Those Who Make Regular Visits: Implications for Adherence to Topical Glaucoma Medications. Ophthalmol Ther. 2016; 5: 207-214.

18. Novak JR, Anderson JR, Johnson MD, Hardy NR, Walker A, Wilcox A, et al. Does Personality Matter in Diabetes Adherence? Exploring the Pathways between Neuroticism and Patient Adherence in Couples with Type 2 Diabetes. Appl Psychol Health Well Being. 2017; 9: 207-227.

19. Axelsson M, Ekerljung L, Lundbäck B, et al. Personality and unachieved treatment goals related to poor adherence to asthma medication in a newly developed adherence questionnaire-a population-based study. Multidiscip Respir Med. 2016; 11: 42.

20. Jokela M, Elovainio M, Nyberg ST, Tabák AG, Hintsa T, Batty GD, et al. Personality and risk of diabetes in adults: pooled analysis of 5 cohort studies. Health Psychol. 2014; 33: 1618-1621.

21. Juch H, Lupattelli A, Ystrom E, Verheyen S, Nordeng H. Medication adherence among pregnant women with hypothyroidism-missed opportunities to improve reproductive health? A cross-sectional, web-based study. Patient Educ Couns. 2016; 99: 1699-1707.

22. Lee JL, Eaton CK, Loiselle Rich K, Reed-Knight B, Liverman RS, Mee LL, et al. The interactive effect of parent personality and medication knowledge on adherence in children awaiting solid organ transplantation. Health Psychology. 2017; 36: 445-448.

23. Vroegindeweij $A$. Type $D$ personality versus the Big Five personality traits and the experience of Social Anxiety [theses]. Bachelor Thesis Psychology \& Health. 2017

24. Moryś JM, Bellwon J, Jeżewska M, Adamczyk K, Gruchała M. The evaluation of stress coping styles and type $D$ personality in patients with coronary artery disease. Kardiol Pol. 2015; 73: 557-566.

25. Keenan J. Improving adherence to medication for secondary cardiovascular disease prevention. Eur J Prev Cardiol. 2017; 24: 29-35.

26. Annagur BB, Demir K, Avci A, Uygur OF. Impact of a Type D Personality on Clinical and Psychometric Properties in a Sample of Turkish Patients With a First Myocardial Infarction. J Psychiatr Pract. 2017; 23: 3-10.

27. Hilliard RC, Brewer BW, Cornelius AE, Van Raalte JL. Big five personality characteristics and adherence to clinic-based rehabilitation activities after ACL surgery: a prospective analysis. The Open Rehabilitation Journal. 2014; 7: 1-5. 